\title{
ASPECTOS TEÓRICO-METODOLÓGICOS DA HISTÓRIA E SUA APLICABILIDADE NA PRÁTICA DE ENSINO
}

\author{
Leandro Mendonça Barbosa ${ }^{1}$ \\ leandromemorialista@gmail.com
}

\begin{abstract}
RESUMO:
É perceptível que os rumos no estudo acerca das ciências da educação têm se modificado com os novos olhares que os intelectuais e os próprios educadores estão tendo desta teoria científica. Destarte quando se vai para a prática desta teoria, quando do momento em sala de aula, muitas vezes esta ainda é pouco dinâmica e muito menos discutida e analisada do que sua esfera teórica. O que pretendemos com este artigo é creditar uma importância dos aspectos teórico-metodológicos discutidos na ciência histórica e da mesma importância que se faz aplicar esta metodologia na prática de ensino com alunos de graduação, para que estes, por sua vez, apliquem em salas de aulas do ensino regular. $\mathrm{Na}$ primeira parte desta reflexão elucidaremos como a teoria e o tratamento de fontes foi enxergado pelo campo tradicional da história - os ditos positivistas - e a aplicabilidades destes conceitos teóricometodológicos em uma pesquisa prática; no segundo momento analisaremos brevemente a prática teórico-metodológica em uma pesquisa histórica. Finalmente, no terceiro momento deste artigo analisaremos duas realidades de salas de aula propostas por dois professores de Prática de Ensino em História de duas universidades federais distintas e tentaremos compreender os métodos utilizados em aula para formulação de conceitos históricos.

Palavras-chave: Conceitos teórico-metodológicos; historicidade de um conceito; Prática de Ensino em História
\end{abstract}

\section{THEORETICAL AND METHODOLOGICAL ASPECTS OF THE HISTORIC RESEARCH AND ITS APPLICABILITY AT THE HISTORY TEACH PRACTICE}

\begin{abstract}
:
It is noticeable that the course of study on science education is being changed with the new ways of looking that intellectuals and educators are having of this scientific theory. Thus when you go to the practice of this theory, at the classroom, many times this is still not much dynamic and much less discussed and studied than at the theoretical sphere. We want this article to credit an importance of theoretical and methodological issues discussed in historical science and, in the same importance, to apply this methodology at the teaching practice with graduation students, so that they apply at the classrooms. At the first part of this reflection we'll elucidate how the theory and treatment of founts was seen by the traditional domain of history - the positivist - and the applicability of these theoretical and methodological concepts in a practice research; at the second review we'll briefly analyze the theoretical and methodological practice in a historical research. Finally, at the third time of this article we'll analyze two classrooms realities proposed by two Practice of Teaching in History teachers from two distinct federal universities and try to understand the methods used in class for the formulation of historical concepts.

Keywords: Theoretical and Methodological concepts; historicity of a concept; Practice of Teaching in History.
\end{abstract}




\section{Introdução}

A preocupação com as analises documentais sempre foi motivo de reflexão entre os profissionais das ciências humanas. Desde o século XIX, quando as humanidades atingiram o ápice de seu conceito de cientificismo, os documentos foram imprescindíveis para a difusão desta idéia, pois estes eram tratados como verdadeiras "provas". Através da documentação, a História e outras ciências ligadas comprovavam quase que matematicamente processos ou acontecimentos históricos.

Durante várias décadas, as teorias tradicionais dominaram a visão quando da leitura de documentos históricos. No século XX, outras teorias passaram a predominar no domínio das ciências históricas. A Escola dos Annales e as novas releituras do marxismo são dois emblemáticos exemplos de como a visão sobre a metodologia da análise documental foi modificando e ganhando novas roupagens.

Neste trabalho, particularmente, pretendemos elucidar algumas destas teorias e metodologias e traçar uma historicidade entre elas. Mas também é de nosso interesse perceber como estas teorias aparecem em uma prática, e o ambiente da disciplina Prática de Ensino em História foi o escolhido por nós. Através desta disciplina, os professores podem enfim mostrar como as análises metodológicas da história podem ser aplicadas em uma realidade social, como a sala de aula.

\section{Teoria e Metodologia da História: a formulação dos conceitos históricos}

Neste primeiro ponto de nossa exposição tentaremos elucidar a historicidade do método teórico da história e sua aplicabilidade nas diversas fontes históricas e nos processos que estas representam. Comecemos com a idéia de método de pesquisa elaborada pela chamada história tradicional - ou positivista - e como esta enxergava o método aplicado a uma pesquisa histórica. Centrar-nos-emos em dois autores que consideramos como primordiais para o entendimento de como a história tradicional lidava com o tratamento de fontes. O primeiro é o inglês Robin George Collingwood; lançaremos mão de sua obra A Idéia de História, publicada postumamente, em 1946.

Nesta obra o autor traça um panorama de como a história deve ser tratada para ser considerada uma ciência - algo muito buscado pelo positivismo. Interessa-nos o capítulo três, intitulado "As Provas Históricas"; neste capítulo Collingwood discute como as fontes ${ }^{2}$ devem ser tratadas como verdadeiras provas que torna uma pesquisa realmente científica. $\mathrm{O}$ autor não acredita que um levantamento de hipóteses eleve a pesquisa histórica à ciência; somente a história tratada como fato é que poderá dar credito a mesma: "Na história, não são hipóteses, são factos, que se apresentam à observação do historiador." (COLLINGWOOD, 1981:309).

Estes fatos são sustentados pelas provas históricas, que comprovam que tal evento realmente ocorreu e obteve uma "causa e uma consequiência". Percebemos que a idéia de Coolingwood sobre o método de pesquisa histórica sempre deve ser tratado por fontes que provam o fato, e fontes escritas. Somente com fontes textuais que provam o fato é que se estará realizando uma pesquisa histórica; se estará "falando historicamente":

Se eu disse: "Lembro-me de ter escrito uma carta a Fulano, na semana passada" - temos uma afirmação da memória, mas não uma afirmação histórica. Todavia, se eu acrescentar: "e a minha memória não está a atraiçoar-me, pois, tenho aqui a resposta dele" - então estou a basear, numa prova, uma afirmação acerca do passado. Estou a falar históricamente. (COLLINGWOOD, 1981:311) 
Adentrando sobre a questão da memória como fonte histórica a ser utilizada em uma pesquisa, Colingwood realiza uma discussão sobre o testemunho. Embora não descarte completamente o testemunho, este coloca que é uma fonte a ser superada, quando da existência de provas documentais. Um testemunho não pode ser tratado como conhecimento histórico em uma pesquisa, haja vista que este não se configura como um conhecimento científico. O testemunho deixa de ser um testemunho quando há provas que o reafirmem:

\begin{abstract}
Não é conhecimento científico, porque não pode ser justificado recorrendo aos fundamentos em que ele se baseia. A partir do momento que existem tais fundamentos, já não se trata mais de testemunho. Quando o testemunho é reforçado pelas provas, a nossa aceitação dele deixa de ser aceitação dum testemunho como tal; é a afirmação de algo que se baseia em provas, isto é, conhecimento histórico. (COLLINGWOOD, 1981:315-316)
\end{abstract}

Ainda na questão do testemunho como método analítico histórico, Colingwood trata deste tipo de tratamento de fontes como a "história de cola e tesoura": "A história construída com base na extracção e combinação dos testemunhos de diversas fontes chamarei história de cola e tesoura." (COLLINGWOOD, 1981:316). O autor afirma que tanto na Antiguidade como na Idade Média este foi o único tipo de história conhecida; os historiadores realizavam suas pesquisas ouvindo uma série de relatos e reunindo-os em uma narrativa ordenada cronologicamente (COLLINGWOOD, 1981:317). Vários são os autores - como Arnaldo Momigliano e François Hartog - que discordam de Collingwood e analisam o método histórico grego contido nas obras de Heródoto, Tucídides e outros. É evidente que estes historiadores do mundo antigo e do medievo não poderiam ter um compromisso científico com a história, quando o conceito de ciência que Collingwood exige em seu método foi formulado posteriormente. Exigir a história científica de autores clássicos torna-se um anacronismo.

Contudo não podemos cair no equívoco de acreditarmos que Collingwood poderia cair na ingenuidade de acreditar piamente nas fontes, mesmo elas sendo escritas. Ele retoma Vico - um dos primeiros pensadores, ainda no início do século XVIII a realizar uma reflexão sobre a idéia de história crítica - para discutir a questão da reflexão sobre uma fonte em uma pesquisa histórica. A "história de cola e tesoura" seria exatamente a simples reunião de documentos sem uma devida análise crítica do que estes poderiam representar:

Quem tiver lido Vico [...]deve ter ficado a saber que o problema mais importante a propósito de qualquer afirmação contida numa fonte não é verificar se ela é verdadeira ou falsa, mas descobrir o que significa. E perguntar o que é que ela significa é abandonar o mundo da história de cola e tesoura, trocando-a por um outro mundo, em que a história não se escreve copiando os testemunhos extraídos das melhores fontes, mas chegando a conclusões pessoais. (COLLINGWOOD, 1981:319)

Após esta constatação do tratamento de fontes que o campo tradicional e positivo da história realizou, entraremos em outra discussão: a aplicabilidade de certas leis teóricas nos processos históricos. É o que muito se discutiu nas décadas de vinte e trinta na Áustria, com o Círculo de Viena, tendo a idéia se alastrado no restante da Europa e na América do 
Norte a partir do final da década de trinta, com a perseguição dos integrantes do grupo - de maioria judia - pelo regime nazista, provocando o exílio da maioria dos estudiosos do Círculo.

O sistema filosófico do Círculo de Viena é chamado de "positivismo lógico", pois aliava o já método positivo de análise de fatos e fontes históricas com alguns campos das ciências exatas e naturais, como a lógica e a física. As idéias de integrantes do Círculo influenciaram grandes nomes do historicismo, como Karl Pooper. Aqui analisaremos a idéia de um estudioso, o filósofo alemão Carl Hempel, e suas idéia sobre a aplicação de leis gerais à pesquisa histórica. O texto intitula-se "Explicação e Leis" e se encontra dentro da obra Teorias de História, organizada por Patrick Gardiner. O texto baseia-se na prova de que é possível as ciências humanas obterem leis gerais que expliquem todos os seus fenômenos, assim como acontece nas outras ciências, como as exatas e as naturais.

Logo no início de seus escritos Hempel nos dá a definição do que seriam estas leis gerais: "Por lei geral, entenderemos aqui uma afirmação de forma condicional e universal capaz de ser confirmada ou infirmada por meio de adequadas descobertas empíricas." (HEMPEL, 1964:422). A aplicabilidade destas leis se daria através de uma observação empírica do fenômeno histórico a ser estudado; suas causas e consequiências - para utilizar dois termos gratos aos positivistas - através do que as fontes nos demonstram. O filósofo descreve a investigação de um radiador lançando mão de leis físicas e dividindo os processos de análise em grupos, sendo que o grupo 1 afirmaria as condições determinantes, ao passo que o grupo 2 seriam as leis gerais em que se baseia as explicações:

Suponhamos que o evento que se pretende explicar é a ruptura do radiador de um automóvel numa noite fria. As frases do grupo 1 podem afirmar as seguintes condições iniciais e condições limites: o carro ficou na rua a noite toda. $\mathrm{O}$ radiador, de ferro, estava completamente cheio de água e tinha a tampa bem fechada e aparafusada. Durante a noite, a temperatura baixou de $39^{\circ} \mathrm{F}$. à tardinha para $25^{\circ} \mathrm{F}$. na manhã seguinte; a pressão atmosférica manteve-se normal. A pressão de ruptura do material de que o radiador é feito é tal e tal. O grupo 2 haveria de conter leis empíricas como as que se seguem: A pressão atmosférica normal, a água gela abaixo de $32^{\circ} \mathrm{F}$. abaixo de $39,5^{\circ} \mathrm{F}$., a pressão de uma massa de água aumenta à medida que a temperatura desce, se o volume se mantiver constante, ou se diminuir, quando a água gela, a pressão eleva-se de novo. A partir de afirmações destes dois tipos é possível deduzir por raciocínios lógicos a conclusão de que o radiador rebentou durante a noite: estabeleceu-se uma explicação para o evento em causa. (HEMPEL, 1964:423)

Percebemos que a intenção de Hempel com este exemplo muito bem trabalhado é seguir o exemplo das análises exatas - neste caso a física e a meteorologia - para uma possível aplicação de leis que explicasse os processos históricos. O positivismo lógico de Carl Hempel - que assim como Collingwood, também requisita uma cientificidade história - acredita que somente lançando mão das mesmas análises que os cientistas naturais é que poderá ser encontrada uma história científica:

Neste aspecto, não existe, porém, qualquer diferença entre a história e as ciências naturais, tanto uma como a outra, só em termo de conceitos gerais podem explicar os respectivos temas, e à história não é mais nem menos possível 'apreender a individualidade única' dos seus obectos de estudo do que à física e à química. (HEMPEL, 1964:424) 
Hempel vai além quando da formulação e explicação de suas leis gerais. O autor afirma que quando existem leis gerais que regem o processo analisado, os efeitos podem ser previstos de antemão e as análises da pesquisa ganhar um foco diferente daquele que não é regido por leis: "Assim, (...), as condições iniciais e as leis gerais que o astrônomo aduziria para explicar um determinado eclipse do sol são as mesmas que podiam igualmente ter bastado para prever o eclipse antes de ele ter lugar." (HEMPEL, 1964:425).

Hoje, quando se conhece várias especificidades tanto temporais como sociais de vários fenômenos históricos distintos, fica difícil aceitar a idéia de que leis gerais, assim como as que regem as ciências exatas, regeriam as causas nos processos históricos. Porém devemos creditar a Hempel - e aos positivistas de um modo geral, desde Ranke - o trabalho de retirar a história do papel de literatura ou narrativa ficcional que por muitas vezes esta foi colocada. A pesquisa histórica vista como método científico muito deve a estes eruditos dos séculos XVIII e XIX e seu tratamento sistemático das fontes.

Destarte, é o século XX que vemos nascer algumas novas abordagens acerca do tratamento de documentos. Com a fundação da corrente dos Annales, através da revista Annales d'histoire économique et sociale, em 1929, por Lucien Febvre e Marc Bloch, temos uma nova abordagem na metodologia; se não houve uma revolução, ao menos uma nova proposta - pertinente para alguns, para outros nem tanto - surge no cenário das ciências humanas. Todas as manifestações do homem tornam-se documentos passíveis de reflexão, tanto o imaterialismo quanto os documentos não tradicionais - diga-se não escritos - passam a fazer-se como história:

A história faz-se com documentos escritos, sem dúvida. Quando estes existem. Mas pode fazer-se, deve fazer-se sem documentos escritos, quando não existem. Com tudo o que a habilidade do historiador the permite utilizar para fabricar o seu mel, na falta das flores habituais. Logo, com palavras. Signos. Paisagens e telhas. Com as formas do campo e das ervas daninhas. Com os eclipses da lua e a atrelagem dos cavalos de tiro. Com os exames de pedras feitos pelos geólogos e com as análises de metais feitos pelos químicos. Numa palavra, com tudo o que, pertencendo ao homem, depende do homem, serve o homem, exprime o homem, demonstra a presença, a atividade, os gostos e as maneiras de ser do homem. (FEBVRE, apud, LE GOFF, 1996:540)

No "Prefácio" do livro Linhagens do Estado Absolutista, o historiador integrante do marxismo inglês Perry Anderson discute como a sua pesquisa será guiada metodologicamente e quais os pressupostos teóricos que este lança mão para análise de seu objeto. Na página oito existem duas passagens que Anderson critica o uso de leis gerais na história: "Por um lado, constroem-se ou pressupõem-se modelos gerias 'abstratos' (...), sem preocupação com suas variações reais; por outro lado, exploram-se casos localizados 'concretos', sem referência às suas implicações ou interconexões recíprocas." (ANDERSON, 1995:8).

A crítica está essencialmente na insuficiência de leis gerais quando do recorte de um objeto específico - no caso da obra a implantação do Estado absolutista através da evolução burguesa e da formação do Estado capitalista. As leis de um modo geral não enxergar as especificidades contidas em cada pesquisa: "Sustenta-se que as leis científicas [...]vigoram apenas para as categorias universais: os objetos particulares são destinados ao domínio do fortuito." (ANDERSON, 1995:8) As especificidades contidas em uma pesquisa histórica devem ser levadas em conta e para isto os referencias teórico-metodológicos 
devem estar muito bem estagmentados e o conhecimento sobre o objeto pesquisado é primordial:

[...]dentro das fronteiras do continente explorado nestas paginas - a Europa - fez-se um esforço relativamente sistemático para dar um tratamento complementar e equivalente às suas regiões ocidental e oriental, tal como na discussão precedente sobre o feudalismo. [...]Embora a divisão entre Europa ocidental e Europa oriental seja um lugar-comum intelectual, raramente foi objeto de uma reflexão histórica direta e sistemática. (ANDERSON, 1995:9)

Em relação à escolha e ao recorte do objeto - questão primordial em uma pesquisa histórica - também é abordada por Anderson em seu prefácio. A obra inova por não delimitar um espaço geográfico e, de certa forma, também não temporal. $\mathrm{O}$ recorte presente no livro é o de um objeto conceitual - o absolutismo:

[...]a escolha do objeto deste estudo [...]determinou uma articulação temporal distinta daquela dos gêneros ortodoxos da historiografia. Os quadros de referência tradicionais da literatura histórica ou são países específicos, ou período determinados. A ampla maioria da investigação qualificada é estritamente efetuada dentro de limites nacionais; e onde uma obra supera tais fronteiras em direção a uma perspectiva internacional, geralmente se restringe a uma época delimitada. (ANDERSON, 1995:9-10)

Uma pesquisa histórica deve ter seu objeto a ser abordado, destarte não poderíamos abarcar todo o aspecto de um objeto - mesmo ele sendo conceitual - se não delimitarmos suas fronteiras. Poderemos estudar a história do medo, todavia o medo que os marinheiros de Odisseu possuíam das sereias e o medo que os Estados Unidos têm de novos ataques terroristas que abalariam o novo governo não devem ser trancafiados nas mesmas leis que os explicariam.

Na última página de seu prefácio temos o exemplo mais claro da aplicabilidade de um conceito. Como marxista Perry Anderson é conhecedor no materialismo histórico e o utiliza em sua pesquisa histórica. Em seu prefácio este alerta para o fato da chamada "história vista de baixo" - utilizada tanto por não-marxistas como por marxistas - negar um dos axiomas do materialismo histórico: que a luta entre as classe se resolve em última instância no campo político da sociedade, e não no econômico e no cultural: "Em outras palavras, é a construção e a destruição dos Estados que sela as modificações básicas nas relações de produção, enquanto subsistirem as classes." (ANDERSON, 1995:11). Embora o autor possa estar fazendo uso de um determinismo histórico - sobrepondo a política às outras esferas de análise social - é mister que este aplica um método que acredita - não importa qual - a sua pesquisa, algo que é esperado de um historiador. Da mesma forma é importante trabalharmos a linguagem como modificador de um conceito (KOSELLECK, 1992:137). Conforme a noção da palavra se modifica com o passar dos tempos, seu conceito também é modificado e o pesquisador deve estar atento antes de utilizá-lo em suas análises.

\section{Aplicabilidade de conceitos históricos na Prática de Ensino em Historia}

Faremos nesta parte de nossa exposição uma breve análise acerca do tratamento de fontes na pesquisa histórica através de aspectos teórico-metodológicos que a legitimem, 
posteriormente, veremos duas propostas de trabalho documental aplicados à prática da sala de aula de duas distintas universidades.

É sabido que a bibliografia que aborda o tema da discussão de métodos na pesquisa histórica é infindável. Aqui trabalharemos com o livro Dinâmica da Pesquisa em Ciências Sociais: os pólos da prática metodológica. Nele, os autores elucidam no capítulo três o pólo teórico da pesquisa científica. Os autores concordam com Collingwood quando colocam que a simples reunião de fato não consiste como progresso de pesquisa (BRUYNE; HERMAN \& SCHOUTHEETE, 1982:101). A pesquisa não deve ser dissociada da teoria, pois corremos o risco de adentrarmos em uma discussão do senso comum que levaria a equívocos quando da análise de fontes de pesquisa:

A teoria assim concebida impregna todo o processo concreto da pesquisa, é imanente a toda observação empírica; toda experimentação, no sentido mais amplo do confronto com o real, é uma questão colocada ao objeto real, sobre o qual se baseia a investigação, em função da teoria construída para apreendê-lo. (BRUYNE; HERMAN \& SCHOUTHEETE, 1982:101)

Queremos ressaltar a constatação de extrema importância quando do início de uma pesquisa. É imprescindível a pesquisa das fontes vir anteriormente às análises teóricas. Do contrario, estaríamos "forçando" a fonte a se adequar à teoria, quando deveria ser o contrário. Entretanto os autores alertam para o fato de não se deixar levar pelas fontes em uma análise leviana; por isso a teorização e a metodologia devem vir logo após o primeiro contato com o objeto estudado:

A teorização inicia-se, portanto, no momento em que começa a pesquisa e a marcação constante e explícita do nível de teorização torna-se primordial; a posição dos objetos de investigação comanda a pertinência, a coerência e a verificabilidade das teorias. (BRUYNE; HERMAN \& SCHOUTHEETE, 1982:108)

Após esta discussão sobre o pólo teórico aplicado à pesquisa histórica, e antes de adentrarmos na discussão sobre a Prática de Ensino em História, veremos brevemente alguns exemplos da prática de aplicação de um conceito teórico em uma pesquisa, com o recorte de objeto e cronologia delimitados. Qual é, afinal, a importância e a aplicabilidade de todos estes conceitos aliados à pesquisa em uma sala de aula? Neste último momento iremos elucidar duas propostas realizadas por dois professores da disciplina de Prática de Ensino em História de duas renomadas universidades federais.

O primeiro texto que iremos trabalhar é o do professor Fernando Seffner, da Universidade Federal do Rio Grande do Sul. O texto tem por título "Teoria, metodologia e ensino de História" e está publicado em uma coletânea organizada por diversos intelectuais intitulada Questões da Teoria e Metodologia da História. O autor começa a discussão descrevendo uma experiência com os alunos de graduação durante suas aulas, quando da discussão sobre a aplicabilidade de campos teórico-metodológicos nas aulas de história do ensino regular. Descartando aqueles alunos que desmerecem ou rejeitam o tema, Seffner constata que existe uma confusão entre "teoria" e "posição política"; alunos militantes da esquerda respondem de chofre: "utilizarei a teoria marxista" (SEFFNER, 2000:259). Embora seja uma teoria metodologicamente possível de ser aplicada, o conceito acaba sendo passado para os alunos de forma simplista, onde a ideologia supera a discussão teórica. Para o autor, a teoria deve ser passada em forma de conceitos da realidade 
contemporânea do aluno, para que este tenha condições de elaborar sua própria teoria quando do assunto abordado: "O professor deve orientar o trabalho levando o aluno a perceber a relação entre posição na estrutura social e visão do processo histórico, o que traz implicações para o conceito de verdade histórica." (SEFFNER, 2000:260).

Trabalhar com teoria e metodologia em sala de aula pode se tornar um fardo tanto para o professor quanto para o aluno, se o docente não pensar as definições operacionais que visem à escola e o entendimento do aluno, conforme a sua vivência e seu meio. Certamente tratarmos a teoria aplicada aos processos históricos como realizamos nesta exposição em uma sala de aula será praticamente impossível o aluno tomar para si a discussão. Os conceitos devem ser trabalhados a partir de um acontecimento histórico que convide o aluno a reflexão:

[...]ao fazer leituras a respeito dos presidentes chilenos do século XX, o aluno deverá ser capaz de efetuar nomeações a partir de dois conceitos: regimes democráticos e regimes autoritários. Ao fazer esse exercício teórico, ele vai entrar em contato com as diferentes possibilidades de interpretação, ou de construção, do fato histórico. (SEFFNER, 2000:261)

O tratamento de fontes históricas é valido para ajudar nesta reflexão teórica. Trabalhar com jornais que acompanharam, por exemplo, a ascensão de Pinochet, colocaria o aluno em contato direto com aquela realidade, e este poderia, com a ajuda do professor, concluir que a ditadura chilena foi completamente ruim por ter matado tantas pessoas ou completamente boa por ter propiciado um crescimento econômico. O método interdisciplinar, ainda segundo Seffner, seria essencial para trabalhar com a idéia de definições de conceitos históricos em sala de aula. Aliando a História a Economia, Antropologia, Filosofia, entre outras ciências é que ajudaremos o aluno a formular seu próprio conceito e passar a enxergar a história não mais como uma narrativa organizada dos fatos:

Assumindo isso, temos que perceber que o ensino da História deve abrir espaço para tratar de temas e categorias conceituais que pertencem até mais diretamente ao terreno de outras disciplinas do social, mas que se tornam importantes na História, pois é através delas que nossa disciplina deixa de ser puro relato do que aconteceu. (SEFFNER, 2000:263)

A reflexão teórico-metodológica da pesquisa histórica realizada em sala de aula torna a História uma disciplina crítica e do pensamento crítico: "Orientar o aluno para o estudo de situações históricas complexas implica lidar com o processo de reescrita da História, transformando seu ensino em uma oportunidade de aprendizado de elementos teórico-metodológicos." (SEFFNER, 2000:273). Estas reflexões não podem ser levantadas levianamente; é preciso que o professor organize o pensamento e os debates em sala, por isso a importância do professor ter conhecimento de pesquisa histórica e dos métodos utilizados para tal.

Fernando Seffner coloca uma proposta de aula organizada em momentos que propiciariam a fácil assimilação de conceitos por alunos: o primeiro momento seria a apresentação do conceito, como estado, ideologia, público, privado, etc. aliando à realidade social do aluno; no segundo momento contemplar estes conceitos dentro de uma fonte histórica - como coleta de jornais, ou execução de projetos para investigar a história da família e da escola -; o terceiro momento seria aumentar a complexidade tanto da pesquisa como da utilização dos conceitos, no estudo de um conjunto de informação históricas sobre 
um país, um episódio, um povo ou uma guerra (SEFFNER, 2000:279-280); desta forma o aluno vai gradativamente assimilando o conceito à realidade da fonte histórica com que ele se depara em sala: "Os conceitos devem ser entendidos como ferramentas que o aluno constrói e utiliza no sentido de tentar compreender [...]fenômenos sociais e situações históricas." (SEFFNER, 2000:280).

Se o texto que trabalhamos agora tratou de uma reflexão geral dos conceitos da pesquisa aplicados à realidade de sala de aula, o texto que iremos a partir deste ponto analisar trata de uma experiência com um único conceito e uma única espécie de abordagem. O texto de Ricardo Oriá, publicado na obra organizada por Circe Bittencourt que tem como título $O$ Saber Histórico na Sala de Aula trata de uma realidade específica e com uma pesquisa histórica também específica. $\mathrm{O}$ autor é professor de Prática de Ensino em História da Universidade Federal do Ceará e o texto, cujo título "Memória e Ensino da História" torna-se auto explicativo à medida que tem o referencial teórico na primeira frase: "memória histórica" (ORIÁ, 2004:128). O professor narra uma experiência com seus alunos de graduação quando da discussão e formulação de um conceito - o de "patrimônio cultural" - e a aplicabilidade do mesmo em fontes históricas - o próprio patrimônio utilizadas na sala de aula do ensino regular.

O texto trata do abandono do conceito de "patrimônio histórico e artístico" por se tratar se restringir aos bens materiais. Já o conceito de "patrimônio cultural" enquadra outras noções culturais, como o meio ambiente, a comida e dança. O termo "patrimônio artístico e histórico" dependia de órgãos oficias que o nomeasse como tal, órgão que não levavam em consideração outros critérios de preservação (ORIÁ, 2004:132). É esta primeira noção que deve ser passada ao aluno: quando o mesmo vai trabalhar com "patrimônio cultural", saberá com que conceito estará lidando e formulará seus próprios métodos de abordagem.

O patrimônio cultural, de acordo com o autor, é uma "[...]terminologia substitutiva à de 'patrimônio histórico e artístico', é constituída de unidades designadas 'bens culturais' (ORIÁ, 2004:132); os "bens culturais" são toda a produção humana, seja ela intelectual, natural ou material. Dividindo este patrimônio cultural em grupos - o primeiro seria o natural, como o meio ambiente; o segundo o conhecimento, as técnicas utilizadas pelo homem e o terceiro é a reunião dos dois primeiros, reúne os bens culturais que englobam toda a sorte de coisa obtidas a partir do próprio meio ambiente e do saber-fazer humano - o aluno poderá trabalhar com noções e conceito cabíveis com sua realidade na sala de aula, no bairro e na vida:

Podemos, pois, concluir que o chamado patrimônio cultural engloba tanto o histórico como o ecológico, o artístico e o científico. O patrimônio cultural de uma dada sociedade é formado por um tripé indissociável em que se contemplam as seguintes dimensões: a dimensão natural ou ecológica, a dimensão histórico-artística e a dimensão documental (ORIÁ, 2004:133).

Neste modelo conceitual torna-se fácil e agradável - tanto para os alunos quanto para o professor - abordar a "memória histórica" através da educação patrimonial, haja vista que os monumentos ${ }^{3}$ são utilizados, seja pelo poder ou pela sociedade como um todo, desde o período greco-romano, ou mais remotamente. A educação patrimonial se dá através de reflexões voltadas para o "patrimônio cultural" e a inclusão no currículo escolar de conteúdos programáticos que versem sobre o conhecimento e a preservação do patrimônio histórico. (ORIÁ, 2004:141). Em Fortaleza, o professor Ricardo Oriá constatou no crescimento urbano em busca de alcançar o "progresso" ações prejudiciais à memória 
patrimonial. Por isso foi montado um projeto no âmbito da disciplina Prática de Ensino em História intitulado Conhecer para Preservar - Preservar para Conhecer: Fortaleza, os lugares da memória, que envolviam estagiários da referida disciplina e escolas da rede pública.

Através da explanação de todos estes conceitos sobre "patrimônio cultural", juntamente com os alunos foi realizada uma pesquisa histórica sobre este tipo de fonte:

Os alunos foram levados a pesquisar e mapear os bens histórico-culturais da cidade, especialmente os imóveis, destacando os seguintes aspectos: em que estado físico se encontravam, sua condição jurídica (bem tombado ou não, integra ou não área de preservação ambiental, possui legislação específica de proteção, etc.) e o atual uso social dado ao mesmo. (ORIÁ, 2004:144)

Os alunos, após a compreensão dos conceitos, sentem-se convidados a questionar àquela fonte que está defronte, e analisar criticamente quando de uma pesquisa histórica proposta por seu professor.

Adentrando na discussão do documento/monumento proposta por Jacques Le Goff, podemos encarar estas experiências dos professores Fernando Seffner e Ricardo Oriá e seus respectivos alunos como uma forma de desvendar a documentação:

O documento não é qualquer coisa que fica por conta do passado, é um produto da sociedade que o fabricou segundo as relações de forças que aí detinham o poder. Só análise do documento enquanto monumento permite à memória coletiva recuperá-lo ao historiador usá-lo cientificamente, isto é, com pleno conhecimento de causa (LE GOFF, 1996:545)

Fazendo com que ao alunos percebam o documento como um monumento do poder e das relações sociais - ou até da barbárie, para utilizar um termo caro a Walter Benjamin - estes passam a ter subsídios para uma reflexão acerca do passado de uma maneira crítica e, na medida do possível, mais completa.

\section{Considerações}

Em caráter propositório, é importante tecermos uma reflexão acerca da teoria do trabalho histórico que não se desvincule da prática e do ofício do profissional dentro do fazer em sala de aula. O documento e os aspectos da pesquisa histórica, sejam quais forem as suas interpretações ou abordagens teóricas, devem sempre estar ligados a um projeto que coloque em prática as análises conceituais.

Desta forma, a reflexão que aborde trabalhos históricos que promovam o estreitamento entre o saber histórico e o saber em sala de aula deve sempre inquietar os profissionais destas áreas. Colocar em prática o que já foi muito discutido pela historiografia - desde o positivismo, passando pelo marxismo e pela Escola dos Annales é dar vida a um processo de discussão histórica que tanto fomenta discussões entre seus especialistas.

\section{Bibliografia}


ANDERSON, Perry. Linhagens do Estado Absolutista. $3^{\text {a }}$ edição. Trad. João Roberto Martins Filho. São Paulo: Brasiliense, 1985.

BRUYNE, Paul de; HERMAN, Jacques e SCHOUTHEETE, Marc de. Dinâmica da Pesquisa em Ciências Sociais: os pólos da prática metodológica. Trad. Ruth Joffily. Rio de Janeiro: Francisco Alves, 1982.

COLlingWOOD, R. G. A Idéia de História. 5a edição. Trad. Alberto Freire. Lisboa: Editorial Presença, 1981.

HEMPEL, Carl. G. "Explicação e Leis". In: GARDINER, Patrick (org.). Teorias da História. $3^{a}$ edição. Trad. Vítor Matos e Sá. Lisboa: Fundação Calouste Gulbenkian, 1964.

KOSELLECK, Reinhart. "Uma História dos Conceitos: problemas teóricos e práticos". In: Estudos Históricos. Rio de Janeiro, vol. 5, nº 10, 1992, p. 134-146.

LE GOFF, Jacques. História e Memória. $4^{\mathrm{a}}$ edição. Trad. Bernardo Leitão [et. al.]. Campinas: Editora Unicamp, 1996.

ORIÁ, Ricardo. "Memória e Ensino de História". In: BITTENCOURT, Circe (org.). $O$ Saber Histórico na Sala de Aula. 9a edição. São Paulo: Contexto, 2004.

SEFFNER, Fernando. "Teoria, metodologia e ensino da História". In: GUAZZELLI, César Augusto Barcellos; (et. al.) (orgs.). Questões da teoria e metodologia da história. Porto Alegre: Editora UFRGS, 2000.

\footnotetext{
${ }^{1}$ Mestre em História pela Universidade Federal de Goiás.

2 "Fonte" é um termo caro aos positivistas, pois denota um jorro de informações que saem sozinhas do documento, como uma fonte de água. Este termo já não é utilizado por muitos profissionais nos dias de hoje, que preferem a palavra "documento".

${ }^{3}$ De acordo com Le Goff: "O monumento tem como características o ligar-se ao poder de perpetuação, voluntária ou involuntariamente, das sociedades históricas (é um legado à memória coletiva) e o reenviar a testemunhos que só numa parcela mínima são testemunhos escritos.” (LE GOFF, 1996:536).
}

Artigo recebido em: 22/07/09

Aprovado para publicação em: 25/01/10 